\title{
EFEITO DO NITROGÊNIO INCORPORADO OU EM SUPERFÍCIE NA PRODUTIVIDADE DE MILHO
}

\author{
Andressa Peruzzo ${ }^{1}$, Leticia Lunelli ${ }^{2}$, Mauricio Vicente Alves ${ }^{3 *}$, Cristiano Nunes Nesi ${ }^{4}$ \\ 1 *Engenheira Agrônoma; Cereais Peruzzo Ltda; e-mail: andressaperuzzo@yahoo.com.br \\ ${ }^{2}$ Engenheira Agrônoma; e-mail: lee.lunelli@ hotmail.com \\ 3*Doutor, Professor; Universidade do Oeste de Santa Catarina, Campus de Xanxerê; e-mail: mauricio.alves@unoesc.edu.br \\ ${ }^{4}$ Doutor, Professor na Universidade do Oeste de Santa Catarina, Campus de Xanxerê e Pesquisador na Empresa de pesquisa \\ Agropecuária e Extensão Rural de Santa Catarina - Epagri; e-mail: cristiano.nesi @unoesc.edu.br
}

RESUMO: O objetivo deste trabalho foi avaliar o efeito de doses de nitrogênio $(\mathrm{N})$ incorporado ao solo ou aplicado em superfície, nos componentes do rendimento da cultura do milho. O estudo foi desenvolvido no município de São Domingos, SC, sob um delineamento experimental inteiramente ao acaso com quatro repetições e parcelas subdivididas. Na parcela principal, foi adotado o modo de aplicação de $\mathrm{N}$ (incorporado ou em superfície do solo), sempre ao lado da linha de plantio. Na subparcela foram avaliadas quatro doses de $\mathrm{N}$ aplicado na forma de ureia no estádio V4 da cultura, sendo: testemunha, sem aplicação de N, e 66, 132 e e $198 \mathrm{~kg} \mathrm{ha}^{-1}$ de N. O híbrido utilizado foi o DKB 240 VT PRO2. O número de fileiras por espiga aumentou de forma linear para nitrogênio incorporado e não incorporado. As demais variáveis apresentaram resposta quadrática quando o nitrogênio foi incorporado ao solo e resposta linear quando o $\mathrm{N}$ não foi incorporado, exceto para a massa de mil grãos. O máximo rendimento de grãos foi obtido com $127,3 \mathrm{~kg} \mathrm{ha}^{-1}$ de $\mathrm{N}$ incorporado ao solo e incremento de $11,5 \mathrm{~kg} \mathrm{ha}^{-1}$ de milho para cada $\mathrm{kg} \mathrm{ha}^{-1}$ de $\mathrm{N}$ aplicado em superfície.

Palavras-chave: Zea mays. Adubação nitrogenada. Incorporação. 


\title{
EFFECT OF INCREASING DOSES NITROGEN OR INCORPORATED SURFACE IN CORN PRODUCTIVITY
}

\begin{abstract}
The aim of this work was to evaluate the effect of increasing doses of nitrogen (N) incorporated to the soil or applied on surface over, the yield components of corn. The study was conducted in the municipality of São Domingos. The experiment was conducted in a randomized complete design with four replications in a split plot. The plot was adopted $\mathrm{N}$ application mode (built-in or on the soil surface), always beside the seedig line. Four doses of $\mathrm{N}$ applied were evaluated in the form of urea in the V4 stage of the crop, as follows: control, without $\mathrm{N}$ application; $66 \mathrm{~kg} \mathrm{ha}^{-1}$ of $\mathrm{N} ; 132 \mathrm{~kg} \mathrm{ha}^{-1}$ of $\mathrm{N}$ and $198 \mathrm{~kg} \mathrm{ha}^{-1}$ of $\mathrm{N}$. The hybrid used for the experiment was the DKB 240 VT PRO2. The number of rows per ear increased linearly to incorporated and unincorporated nitrogen. The other variables showed a quadratic response when the nitrogen was incorporated into the soil and linear response when the $\mathrm{N}$ was not incorporated except for the thousand grain weight. The maximum grain yield was obtained with $127.3 \mathrm{~kg} \mathrm{ha}^{-1}$ of $\mathrm{N}$ incorporated into the soil and increase of $11.5 \mathrm{~kg} \mathrm{ha}^{-1}$ of corn for each $\mathrm{kg} \mathrm{ha}^{-1}$ of $\mathrm{N}$ applied to the surface.Key-words: Zea mays. Incorporation. Yield.
\end{abstract}

\section{INTRODUÇÃO}

O milho (Zea mays L.) é o cereal mais consumido no Estado de Santa Catarina, devido principalmente às criações de suínos e aves. Mesmo com produção superior a três milhões de toneladas anuais, o estado importa cerca de 1,5 milhões de toneladas de grãos por ano (SÍNTESE..., 2013). Neste sentido, aprimorar técnicas que proporcionem incremento na produtividade da cultura são desafios da pesquisa agropecuária, pois diminuirá os custos com importação, elevando a renda dos criadores de animais.

Entre os fatores que contribuem para o incremento da produtividade da cultura do milho, a disponibilidade de nitrogênio é um dos mais importantes, pois é o nutriente absorvido em maior quantidade pelas plantas, e o que exerce efeito mais pronunciado na produtividade (SCHERER, 2010). A produtividade e a qualidade do milho são positivamente influenciadas pela adubação nitrogenada, em consequência do aumento nos teores de proteína e nutrientes minerais (PORFIRIO-DA-SILVA et al., 2015). Entretanto, a aplicação de N no solo está sujeita a perdas por volatilização, imobilização, desnitrificação e lixiviação, sendo sua eficiência de utilização pela planta regulada por fatores de solo, climáticos, forma do fertilizante e práticas de manejo (LARA-CABEZAS \& COUTO, 2007). 
Neste sentido, a incorporação da ureia ao solo é uma alternativa para reter maior quantidade de amônio no solo e minimizar as perdas por volatilização (SANGOI et al., 2003). Civardi et al. (2011) concluíram que a ureia incorporada ao solo na cultura do milho em estádio V5, na entrelinha da cultura, proporcionou maiores comprimento de espiga, número de grãos por espiga, massa de cem grãos, produtividade de grãos e da relação entre receita obtida e valor investido em relação a ureia aplicada em superfície.

Neste contexto, o objetivo deste estudo foi avaliar o efeito de doses de $\mathrm{N}$ incorporado ao solo ou aplicado em superfície, nos componentes do rendimento da cultura milho em Sistema Plantio Direto.

\section{MATERIAL E MÉTODOS}

O estudo foi desenvolvido no município de São Domingos, situado no oeste do Estado de Santa Catarina, em uma área localizada a $26^{\circ} 33^{\prime}$ '29' de latitude Sul e 52 $31^{\prime}$ '54' de longitude Oeste, com 635 metros de altitude média. O solo do local é um Latossolo Vermelho distroférrico (EMBRAPA, 2004) manejado em Sistema Plantio Direto. O clima da região é temperado úmido, com verões quentes (Cfa) (ALVARES et al., 2013).

$\mathrm{O}$ experimento foi instalado num delineamento inteiramente casualizado com parcelas subdivididas e quatro repetições. Na parcela principal foram alocados os modos de aplicação de N: incorporado ao solo e aplicado na superfície do solo. Nas subparcelas foram avaliadas doses de $\mathrm{N}$, aplicadas na forma ureia e no estádio V4 da cultura. As subparcelas foram implantadas com dimensões de 2,5 x 2,5 m, e espaçamento de 0,75 m entre linhas. Os tratamentos foram: testemunha sem aplicação de N, 66, 132, e $198 \mathrm{~kg} \mathrm{ha}^{-1}$ de N. A ureia incorporada foi aplicada em sulcos com $5 \mathrm{~cm}$ de profundidade, abertos com enxada há $5 \mathrm{~cm}$ da linha de plantas. O híbrido utilizado foi o DKB 240 VT PRO2, com tecnologia BT, com gene YieldGard, numa população de plantas esperada de 75000 plantas ha $^{-1}$. A semeadura foi realizada em 12 de setembro de 2012, com utilização de $400 \mathrm{~kg} \mathrm{ha}^{-1}$ de adubo com formulação 8-20-20 (N-P-K) na base (CQFS/RS-SC, 2004). A colheita foi realizada 164 após a 
semeadura, colhendo-se as plantas centrais da parcela e descartadas as bordaduras. As espigas foram trilhadas, eliminando as impurezas e os grãos colocados em estufa à $45^{\circ} \mathrm{C}$ para diminuir a umidade a $13 \%$.

Os componentes do rendimento avaliados foram o número de fileiras de grãos por espiga, o número de grãos por espiga, o diâmetro e o comprimento da espiga, a massa de grãos por espiga, massa de mil grãos e o rendimento de grãos. Os dados foram submetidos à análise de regressão linear simples, ajustando-se a equação de regressão linear ( $\mathrm{Y}=\mathrm{a}+\mathrm{bx})$ e quadrática $\left(\mathrm{Y}=\mathrm{a}+\mathrm{bx}+\mathrm{cx}^{2}\right)$. Para a equação de regressão linear, $\mathrm{Y}$ corresponde à resposta medida, $x$ a dose de $\mathrm{N}$, "a" é o intercepto (valor da resposta para $\mathrm{x}=0$ ) e "b" a taxa de incremento na resposta para cada unidade de N. Para a equação de regressão quadrática, Y, x e "a" foram como na regressão linear, "b" é a taxa de variação na origem e "c" mede o grau de curvatura e orientação da concavidade da parábola. Nos casos em que uma equação de regressão quadrática foi ajustada, calculou-se a dose de $\mathrm{N}$ para a máxima eficiência técnica. Para isso, ajustou-se a equação de regressão quadrática parametrizada como um modelo não linear, conforme proposto por Zeviani (2013), de forma que os parâmetros são interpretados diretamente como dose de $\mathrm{N}(\mathrm{Xm})$ para a máxima resposta $(\mathrm{Ym}): \mathrm{Y}=\mathrm{Ym}+\mathrm{c} *\left(\right.$ dose-Xm) ${ }^{2}$. Isto corresponde a igualar a zero a derivada de primeira ordem da função quadrática e determinar $\mathrm{o}$ valor de $\mathrm{x}$ (dose). Todas as análises foram realizadas com o programa $\mathrm{R}(\mathrm{R}$ DEVELOPMENT CORE TEAM, 2015), utilizando-se as funções $\operatorname{lm}$ e nls. A comparação estatística entre os tratamentos ( $\mathrm{N}$ incorporado e não incorporado) se dá pelo ajuste dos modelos linear e quadrático. Quando se escolhe um dos modelos em detrimento do outro, isto significa que a incorporação (ou não) tem efeito significativo na variável resposta. No caso de ajuste de um mesmo modelo para $\mathrm{N}$ incorporado e não incorporado, a comparação é feita pela verificação dos intervalos de confiança para as estimativas dos parâmetros do modelo ajustado. Intervalos de confiança que se sobrepões significa que as estimativas dos parâmetros não diferem entre os tratamentos. 


\section{RESULTADOS E DISCUSSÃO}

O número de fileiras por espiga aumentou de forma linear para nitrogênio incorporado e não incorporado. As demais variáveis apresentaram resposta quadrática quando o nitrogênio foi incorporado ao solo e resposta linear quando o $\mathrm{N}$ não foi incorporado, excetuando-se a a massa de mil grãos (Tabela 1).

Para o número de fileiras de grãos por espiga o incremento observado foi de 0,0014 e 0,0029 fileiras por espiga para cada $\mathrm{kg}$ de $\mathrm{N} \mathrm{ha}^{-1}$ incorporado e não incorporado, respectivamente (Tabela 1). Como os intervalos de confiança das estimativas dos parâmetros não se sobrepõem, pode-se inferir que há diferença significativa entre $\mathrm{N}$ incorporado e não incorporado ao solo. Estes resultados discordam de Civardi et al. (2011) que concluíram que para a variável número de fileiras de grãos por espiga não houve efeito de dose e nem de forma de aplicação do N.

$\mathrm{O}$ diâmetro máximo das espigas $(112,2 \mathrm{~mm}$ ) foi observado com $48,1 \mathrm{~kg}$ de $\mathrm{N}$ ha-1 incorporado. Para N não incorporado o aumento do diâmetro foi linear com 0,0128 mm para cada $\mathrm{kg}$ de $\mathrm{N} \mathrm{ha}^{-1}$ (Tabela 1). Freire et al. (2010) enfatizaram o efeito da aplicação de nitrogênio a lanço, com aumento das doses e consequente aumento do diâmetro das espigas. 
Tabela 1 - Estimativas dos parâmetros para os modelos de regressão quadrático e linear simples, seguidos do coeficiente de determinação e dos respectivos intervalos de confiança, ajustados aos dados dos componentes de rendimento de milho em função de doses de $\mathrm{N}$ (via ureia) incorporado e não incorporado ao solo.

Table 1 - Estimates of the parameters for the model of simple quadratic and linear regression, followed by the coefficient of determination and confidence intervals, adjusted to data of maize yield components due to $\mathrm{N}$ rates (like urea) embedded and not incorporated into the soil.

\begin{tabular}{|c|c|c|c|c|c|c|}
\hline \multirow[b]{2}{*}{ Variável } & \multicolumn{2}{|c|}{ Quadrática } & \multirow[b]{2}{*}{$\mathbf{R}^{2}$} & \multicolumn{2}{|c|}{ Linear } & \multirow[b]{2}{*}{$\mathbf{R}^{2}$} \\
\hline & $\mathbf{X}_{\mathbf{m}}$ & $\mathbf{Y}_{\mathbf{m}}$ & & $\mathbf{a}$ & b & \\
\hline & \multicolumn{6}{|c|}{$\mathrm{N}$ incorporado } \\
\hline \multirow[t]{2}{*}{ Fileiras de grãos/espiga } & - & - & - & 12,7 & 0,0014 & 99,5 \\
\hline & & & & $(12,6 ; 12,7)$ & $(0,0013 ; 0,0016)$ & \\
\hline \multirow[t]{2}{*}{ Diâm. Espiga (mm) } & 112,2 & 48,1 & 99,7 & & - & - \\
\hline & $(108,2 ; 116,2)$ & $(47,9 ; 48,2)$ & & & & \\
\hline \multirow[t]{2}{*}{ Comp. Espiga (cm) } & 113,9 & 16,1 & 99,9 & & - & - \\
\hline & $(112,1 ; 115,7)$ & $(16,0 ; 16,1)$ & & & & \\
\hline \multirow[t]{2}{*}{ Massa de mil grãos (g) } & 336,0 & 97,6 & 96,7 & & - & - \\
\hline & $(331,4 ; 340,6)$ & $(86,9 ; 108,3)$ & & & & \\
\hline \multirow[t]{2}{*}{ Grãos/espiga $\left(n^{\circ}\right)$} & 118,2 & 455,8 & 99,2 & - & - & - \\
\hline & $(110,6 ; 125,7)$ & $(449,4 ; 462,1)$ & & & & \\
\hline \multirow[t]{2}{*}{ Rendimento (t/ha) } & 127,3 & 12,2 & 88,4 & - & - & - \\
\hline & $(87,1 ; 167,6$ & $(11,0 ; 13,3)$ & & & & \\
\hline
\end{tabular}

\section{N não incorporado}

Fileiras de grãos/espiga

Diâm. Espiga (mm)

Comp. Espiga (cm)

Massa de mil grãos (g)

$$
165,1
$$

Grãos/espiga ( $\left.\mathrm{n}^{\circ}\right)$

Rendimento (t/ha)
$(17,9 ; 312,6)$

$\begin{array}{ccc}12,3 & 0,0029 & 97,6 \\ (12,2 ; 12,4) & (0,0024 ; 0,0034) & \\ 44,9 & 0,0128 & 99,5 \\ (44,8 ; 45,1) & (0,0118 ; 0,0138) & \\ 13,6 & 0,0101 & 85,7 \\ (13,1 ; 14,2) & (0,0055 ; 0,0146) & \\ - & - & - \\ 371,3 & 0,2960 & 91,3 \\ (358,7 ; 383,81) & (0,1943 ; 0,3977) & \\ 8,7 & 0,0115 & 84,1 \\ (8,0 ; 9,4) & (0,0060 ; 0,0170) & \end{array}$

${ }^{1}$ Modelos ajustados: $Y=a+b x$ para regressão linear simples e $Y=a+b x+c x^{2}$ para regressão quadrática, parametrizado por Zeviani (2013) para $\mathrm{Y}=\mathrm{Ym}+\mathrm{c}^{*}(\mathrm{dose}-\mathrm{Xm})^{2}$ em que $\mathrm{Xm}$ corresponde à dose de $\mathrm{N}$ para a máxima resposta $\mathrm{Ym}$.. $\mathrm{R}^{2}=$ coeficiente de determinação; ${ }^{\text {ns }}$ Não-significativo. *Significativo a 5\% de probabilidade. - não se aplica.

O comprimento da espiga é um dos caracteres que pode interferir, diretamente, no número

de grãos por fileira e, consequentemente, na produtividade do milho (KAPPES et al., 2009). Para essa característica agronômica, a dose de $113,9 \mathrm{~kg}_{\text {de }} \mathrm{N} \mathrm{ha}^{-1}$ incorporado ao solo resultou maior 
comprimento de espiga (16,1 cm) (Tabela 1). Civardi et al. (2011) chegaram ao valor médio de $13,81 \mathrm{~cm}$ com a dose de $104 \mathrm{~kg} \mathrm{ha}^{-1}$ de $\mathrm{N}$ incorporado. Para o $\mathrm{N}$ não incorporado houve incremento linear a taxa de $0,0101 \mathrm{~cm}$ para cada $\mathrm{kg} \mathrm{ha}^{-1} \mathrm{de} \mathrm{N}$ aplicado. No trabalho de Silva et al. (2005) chegaram a resultados semelhantes, com $\mathrm{N}$ incorporado resultando em um aumento no comprimento da espiga.

O número de grãos por espiga apresentou máximo de 455,8 grãos com aplicação de $118,2 \mathrm{~kg} \mathrm{ha}^{-1}$ de $\mathrm{N}$ incorporado ao solo. Para o $\mathrm{N}$ não incorporado o número aumentou à taxa de 0,296 grãos para cada $\mathrm{kg}$ de $\mathrm{N} \mathrm{ha}^{-1}$ (Tabela 1). Andrioli et al. (2008) aplicando doses de $\mathrm{N}$ entre 60 e $120 \mathrm{~kg} \mathrm{ha-1}$ em cobertura obtiveram melhores resultados na produtividade de matéria seca e de grãos de milho em relação à outras doses.

Em relação à produtividade, a maior média obtida foi com a dose de 127,3 $\mathrm{kg}^{\mathrm{de}} \mathrm{N}^{-} \mathrm{a}^{-}$ ${ }^{1}$ para o $\mathrm{N}$ não incorporado, com resultado de $12,2 \mathrm{t}$ de milho por hectare. Ao nitrogênio não incorporado a produtividade respondeu de forma linear, com incremento de $11,5 \mathrm{~kg}$ de milho para cada $\mathrm{kg}$ de $\mathrm{N}$ aplicado (Tabela 1). Nas duas situações experimentais obteve-se produtividade de grãos acima da média catarinense $\left(6,5 \mathrm{t} \mathrm{ha}^{-1}\right)$ e da região de Xanxerê $(7,9 \mathrm{t}$ $\left.\mathrm{ha}^{-1}\right)($ SÍNTESE..., 2013).

A adubação nitrogenada de cobertura promoveu acréscimos significativos nas características agronômicas e nutricionais do milho com a produtividade máxima de grãos obtida com $151 \mathrm{~kg} \mathrm{ha}^{-1}$ de N (Farinelli \& Lemos, 2012), em consonância com os resultados obtidos no presente estudo. Outro estudo mostrou que a uréia comum incorporada ao solo propiciou maior rendimento de grãos de milho e maior lucratividade do que a uréia revestida aplicada em superfície (CIVARDI et al., 2011). França et al. (2011) constataram um aumento no rendimento de grãos de milho quando houve disponibilidade adequada de nitrogênio, ou seja, quando o teor de matéria orgânica do solo era em torno de $2,5 \%$ ou mais. 


\section{CONCLUSÕES}

A aplicação da ureia ( $\mathrm{N}$ incorporado) foi mais eficiente e refletiu em melhores resultados nos componentes do rendimento quando comparada a aplicação de uréia sem incorporação.

Utilizando-se ureia incorporada é possível definir a dose de $\mathrm{N}$ que confere a máxima resposta para a maioria dos componentes do rendimento, o que não ocorre com uréia não incorporada.

\section{REFERÊNCIAS}

ALVARES, C.A.; STAPE, J.L.; SENTELHAS, P.C.; GONÇALVES, J.L.M.; SPAROVEK, G. Koöppen's climate classification map for Brazil. Meteorologische Zeitschrift, v. 22, n. 6, p.711-728, 2013.

ANDRIOLI, I.: BEUTLER, A.N.; CENTURION, J.F.; ANDRIOLI, F.F;. COUTINHO, E.L.M. Pprodução de milho em plantio direto com adubação nitrogenada e cobertura do solo na pré-safra. Revista Brasileira de Ciência do Solo, Viçosa, v.32, n.4, p.1691-1698, 2008.

CIVARDI, E.A.; SILVEIRA NETO, A.N.; RAGAGNIN, V.A.; GODOY, E.R.; BROD, E. Uréia de liberação lenta aplicada superficialmente e ureia comum incorporada ao solo no rendimento do milho. Pesquisa agropecuária tropical, Goiânia, v.41, p.52-59, 2011.

COELHO, A. M. Manejo da adubação nitrogenada na cultura do milho. Embrapa Circular Técnica 96, Sete Lagoas, MG, Dezembro 2007. 11.

CQFS/RS-SC - COMISSÃO DE QUÍMICA E FERTILIDADE DO SOLO. Manual de adubação e de calagem para os estados do Rio Grande do Sul e Santa Catarina. Porto Alegre, Sociedade Brasileira de Ciência do Solo/Núcleo Regional Sul, ed. 10, 400p. 2004.

EMBRAPA. Empresa Brasileira de Pesquisa Agropecuária. Centro Nacional de Pesquisa de Solos, CNPS. Solos do Estado de Santa Catarina. Boletim de Pesquisa e Desenvolvimento, n. 46, CD Ron, Rio de Janeiro, 2004.

FARINELLI, R.; LEMOS, L. B. Nitrogênio em cobertura na cultura do milho em preparo convencional e plantio direto consolidados. Pesquisa agropecuária tropical, Goiânia, v. 42, n. 1, p. 63-70, 2012.

FRANÇA, S.; MIELNICZUK, J.; ROSA, L.M.G., BERGAMASCHI, H.; BERGONCI, J.I. Nitrogênio disponível ao milho: Crescimento, absorção e rendimento de grãos. Revista Brasileira de Engenharia Agrícola e Ambiental, Campina Grande, v. 15, n. 11, p. 1143 - 1151, 2011.

FREIRE, F.M..; VIANA, M.C.M..; MASCARENHAS, M.H.T .; PEDROSA, M.W.; COELHO, A.M.; ANDRADE, C. DE L.T. DE. Produtividade econômica e componentes da produção de espigas verdes de milho em função da adubação nitrogenada. Revista Brasileira de Milho e Sorgo, v. 9, n. 3, p. 213-222, 2010. 
KAPPES, C.; CARVALHO, M.A.C. DE.; YAMASHITA, O.M.; SILVA, J.A.N. DA. Influência do nitrogênio no desempenho produtivo do milho cultivado na segunda safra em sucessão à soja. Pesquisa Agropecuáraia Tropical, Goiânia, v. 39, n. 3, p. 251-259, 2009.

LARA-CABEZAS, W.A.R.; COUTO, P.A. Imobilização de nitrogênio da uréia e do sulfato de amônio aplicado em pré-semeadura ou cobertura na cultura de milho, no sistema plantio direto. Revista Brasileira de Ciência do Solo, Viçosa, v.31, n. 4, ago. 2007.

OLIVEIRA, J. M. S. D.; CAIRES, E. F. Adubação nitrogenada em cobertura para o milho cultivado após aveia preta no sistema plantio direto. Acta Scientiarum Agronomy, Maringá, v. 25, p. 351-357, 2003.

PORFIRIO-DA-SILVA, V.; MORAES, A.DE; MOLETTA, J.L.; PELISSARI, A.; DIECKOW, J.; OLIVEIRA, E.B. DE. Produtividade do milho em um sistema silviagrícola nos Campos Gerais, PR. Scientia Agraria, Curitiba, v.16, n.1, p.27-32, 2015.

R DEVELOPMENT CORE TEAM. R: A language and environment for statistical computing. R Foundation for Statistical Computing, Vienna, Austria. 2015. ISBN 3-900051-07-0, URL http://www.R-project.org/

SANGOI, L.; ERNANI, P.R.; LECH, V.A.; RAMPAZZO, C. Lixiviação de nitrogênio afetada pela forma de aplicação da uréia e manejo dos restos culturais de aveia em dois solos com texturas contrastantes. Ciência Rural, Santa Maria, v.33, n.1, p.65-70, 2003.

SCHERER, E. E. Calagem e adubação da cultura do milho. In: FILHO, J. A. W.; ELIAS, H. T. A cultura do milho em Santa Catarina. Florianópolis: Epagri, 2010. Cap. 4, p. 163-206.

SILVA, E. C. DA.; BUZETTI, S.; GUIMARÃES, G.L.; LAZARINI, E.; SÁ, M.E. DE. Doses e épocas de aplicação de nitrogênio na cultura do milho em plantio direto sobre latossolo vermelho. Revista Brasileira de Ciências do Solo, Viçosa, v. 29, n. 3, p. 353-362, 2005.

SÍNTESE ANUAL DA AGRICULTURA DE SANTA CATARINA. Empresa de Pesquisa Agropecuária e Extensão Rural de Santa Catarina/Centro de Socioeconomia e Planejamento Agrícola - Epagri/Cepa, Florianópolis, SC. 2013.

ZEVIANI, W.M. Parametrizações interpretáveis em modelos não lineares. Tese (Doutorado). 146 p. Universidade Federal de Lavras, Lavras: UFLA, 2013. 